\title{
Effect of Thyromimetic GC-1 Selective Signaling on Reproductive and Lactational Performance in the Hypothyroid Rat
}

\author{
Estefanía Rinaldini $^{a} \quad$ Fiorella Campo Verde Arboccó $^{a} \quad$ Marcelo Ezquer $^{b}$ \\ Carlos Gamarra-Luques ${ }^{\mathrm{a}, \mathrm{c}}$ María Belén Hapon ${ }^{\mathrm{a}, \mathrm{d}}$ \\ ${ }^{a}$ Consejo Nacional de Investigaciones Científicas y Técnicas (CONICET), Universidad Nacional de Cuyo, Mendoza, \\ Argentina; ${ }^{b}$ Centro de Medicina Regenerativa, Facultad de Medicina Clínica Alemana, Universidad del Desarrollo, \\ Santiago, Chile; 'Facultad de Ciencias Médicas, Instituto de Fisiología, Universidad Nacional de Cuyo, Mendoza,

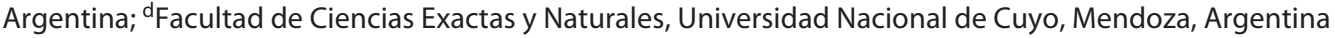

\section{Keywords}

Hypothyroidism · Gestation · Lactation · GC-1 · Pup survival

\begin{abstract}
Introduction: The potential of the thyroid hormone receptor $\beta$ (TR $\beta 1$ ) selective analog GC-1 has been widely proven in animal models and humans. However, its effect on the reproductive stage of the female rat has not been evaluated. Methods: The effect of the administration of GC-1 or equimolar doses of triiodothyronine (T3) was evaluated on the reproductive performance of the hypothyroid female rat and the indirect effect on pup thyroid status, weight, and survival. Results: Hypothyroidism reduced the number of embryos implanted in the uterus, whereas T3 and GC- 1 treatment in hypothyroid females reestablished the number of implanted embryos to normal. Initiation of labor was delayed by hypothyroidism, and T3 replacement treatment reinstated the normal timing of parturition. The administration of GC-1 alone to the lactating mother did not affect pup survival, weight, or thyroidal status. Conclusions: Our findings show the differential effect of thyroid hormone selective signaling during gestation and the indirect exposure of the pups; we also emphasize the plausible use of GC- 1 for treatment of hypothyroid mothers during the lactation period.
\end{abstract}

(c) 2021 European Thyroid Association Published by S. Karger AG, Basel

\section{Introduction}

Thyroid diseases cause menstrual disturbances, reduced fertility, recurrent pregnancy loss, perinatal mortality, and lactational deficit $[1,2]$. We have demonstrated that hypothyroidism delays the onset of parturition, reduces litter size, impairs pup weight, alters hormonal profiles during gestation and lactation, and modifies liver and mammary lipid metabolism in rats $[3,4]$.

The genomic actions of thyroid hormones (THs) are mediated by 2 main thyroid receptor (TR) isoforms, TRa and TR $\beta$, encoded by THRA and THRB genes. The isoforms TR 1 , TR $\alpha 2$, and TR $\beta 1$ are expressed in reproductive tissues, such as the human ovary, placenta, uterus, and mammary gland, and TR $\beta 2$ is restricted to the hypothalamus and pituitary [5-9].

Our previous findings indicate that a deficit of THs alters corpus luteum (CL) function, delaying the onset of parturition in the rat $[10,11]$. It has adverse effects on PRL signaling in the mammary gland, leading to lower milk production and early involution $[12-14,31]$.

The effects of TR isoforms in reproductive tissues have been indirectly demonstrated in animals bearing TRal

Estefanía Rinaldini and Fiorella Campo Verde Arboccó contributed equally to the work.
Correspondence to:

María Belén Hapon, bhapon@mendoza-conicet.gob.ar 
and TR $\beta 1$ mutations. Mice with negative dominant mutations in TRa 1 are not viable, whereas those with heterozygous mutations present a moderate alteration of their thyroid status and have high mortality, fertility impairment, and fewer pups per litter [15]. Females lacking both receptors rarely become pregnant and, if they do so, are unable to sustain lactation [16]. Mice exhibiting mutation on TR $\beta$ are seemingly normal in terms of their reproduction [17].

Altogether, these findings suggest that TR isoforms are differentially expressed in reproductive tissues of humans and rodents and fluctuate depending on the physiological state. Hence, TH signaling outcome seems to depend on selective subtype binding and further activation.

Another approach to identify the selective action of TR in vivo is using thyromimetics. The first compound described with potential use as a selective TR $\beta 1$ thyromimetic was GC-1, now called sobetirome. This compound prevents the undesired TRa1-mediated TH effects, such as an increase in heart rate and muscle or bone catabolism. While GC-1 action has been demonstrated in vitro and in vivo, its effect on the reproductive process has not yet been evaluated in animal models or in humans [18-22]. We hypothesized that GC-1 exerts different actions than T3 due to its selective signaling on the reproductive tissues of hypothyroid rats. Hence, this study aims to demonstrate $\mathrm{TH}$-selective signaling effects on reproductive and lactational performance in hypothyroid rats. In addition, we propose a potential safe usage of GC-1 during gestation and lactation in the rat.

\section{Materials and Methods}

Animals and Experimental Design

Adult female Wistar rats bred in our laboratory, 3-4 months old, weighing 200-230 g and with regular 4-day estrus cycles, were used. They were kept in a light (lights on 06:00-22:00 h) and temperature $\left(22-24^{\circ} \mathrm{C}\right)$ controlled room. Gestational day $(\mathrm{G}) 1$ of pregnancy was defined by the detection of spermatozoa in the vaginal smears the morning after caging with a fertile male the night of proestrus.

Experiments were carried out using 6 groups of $6-8$ rats: (i) euthyroid control (C), (ii) hypothyroid (H), (iii) hypothyroid treated daily with $0.6 \mu \mathrm{g} \mathrm{T} 3 / 100 \mathrm{~g}$ body weight (BW) $(\mathrm{H}+\mathrm{T} 3)$, (iv) hypothyroid treated daily with $0.3 \mu \mathrm{g} \mathrm{GC}-1 / 100 \mathrm{~g} \mathrm{BW}(\mathrm{H}+\mathrm{GC}-1)$, (v) euthyroid rats treated daily with $0.6 \mu \mathrm{g}$ T3/100 g BW (T3), and (vi) euthyroid rats treated daily with $0.3 \mu \mathrm{g}$ GC-1/100 g BW (GC1). Hypothyroidism was induced by administration of 6-propyl2-thiouracil (PTU) at concentrations of 0.05 and $0.1 \mathrm{~g} / \mathrm{L}$ in the drinking water. T3 and GC-1 doses were equimolar and equivalent to twice the physiological dose of T3 $(2 \times)$. Additional groups were treated with double or quadruple T3 dosages (1.2 or $2.4 \mu \mathrm{g}$ T3/100 g BW per day, designated as $4 \times$ and $8 \times$, respectively), or with double or quadruple GC- 1 dosages ( 0.6 or $1.2 \mu \mathrm{g}$ GC- $1 / 100 \mathrm{~g}$ BW per day, designated as $4 \times$ and $8 \times$, respectively) [23]. All treatments started 8 days prior to mating and continued during gestation and lactation (online suppl. Fig. 1; for all online suppl. material, see www.karger.com/doi/10.1159/000516432).

Blood was collected from the tail vein of the mothers on day 7 (G7) or 21 (G21) of gestation or day 14 (L14) of lactation, between 10:00 and 12:00 h. On day 21 of lactation (L21), mothers and pups were sacrificed by decapitation and trunk blood collected. Serum was separated by centrifugation and stored at $-20^{\circ} \mathrm{C}$ until used for hormone determinations.

\section{Reproductive Performance}

Date and time of delivery, number of total/live newborns per litter, pup weight gain, and survival during lactation were registered. A group of dams was sacrificed on G7, and the total number of uterine implantation sites was recorded.

\section{Hormone Determinations}

TSH was measured as previously described [24]. T3 and T4 concentrations were measured by RIA using commercial kits for total hormones [25]. GC-1 did not crossreact with T3 or T4 RIA (online suppl. Fig. 3). For further details, see online suppl. information.

\section{Western Blot Analysis}

Western blot analysis of TR proteins was performed as described in the supplemental information (online suppl. Fig. 2).

\section{Statistical Analysis}

Statistical analysis was performed using one-way ANOVA followed by the Tukey post hoc test to compare between groups and the nonparametric Kruskal Wallis test followed by the Dunn post hoc test to compare groups. The Brown-Forsythe test was performed to determine Gaussian data distribution. The survival curves were compared using the log-rank (Mantel-Cox) test considering a 95\% CI of ratio. All statistical analyses were performed using the software Graph Pad Prism 7 (GraphPad Software, San Diego, CA, USA).

\section{Results}

\section{Effect of GC-1 and T3 Treatment on T3 and TSH} Serum Concentrations in Hypothyroid and Control Rats during Gestation and Lactation

As expected, hypothyroidism increased TSH and reduced T3 levels during the entire gestation and lactation, confirming the thyroid status of the $\mathrm{H}$ group (shown in Fig. 1). In the $\mathrm{H}+\mathrm{T} 3$ group, $\mathrm{T} 3$ and $\mathrm{TSH}$ were reduced at the beginning of gestation, indicating that $\mathrm{T} 3$ treatment compensates the effect of PTU. It is noteworthy that daily administration of T3 was performed after blood sampling. Hormone levels thus reflected the regulation of the 


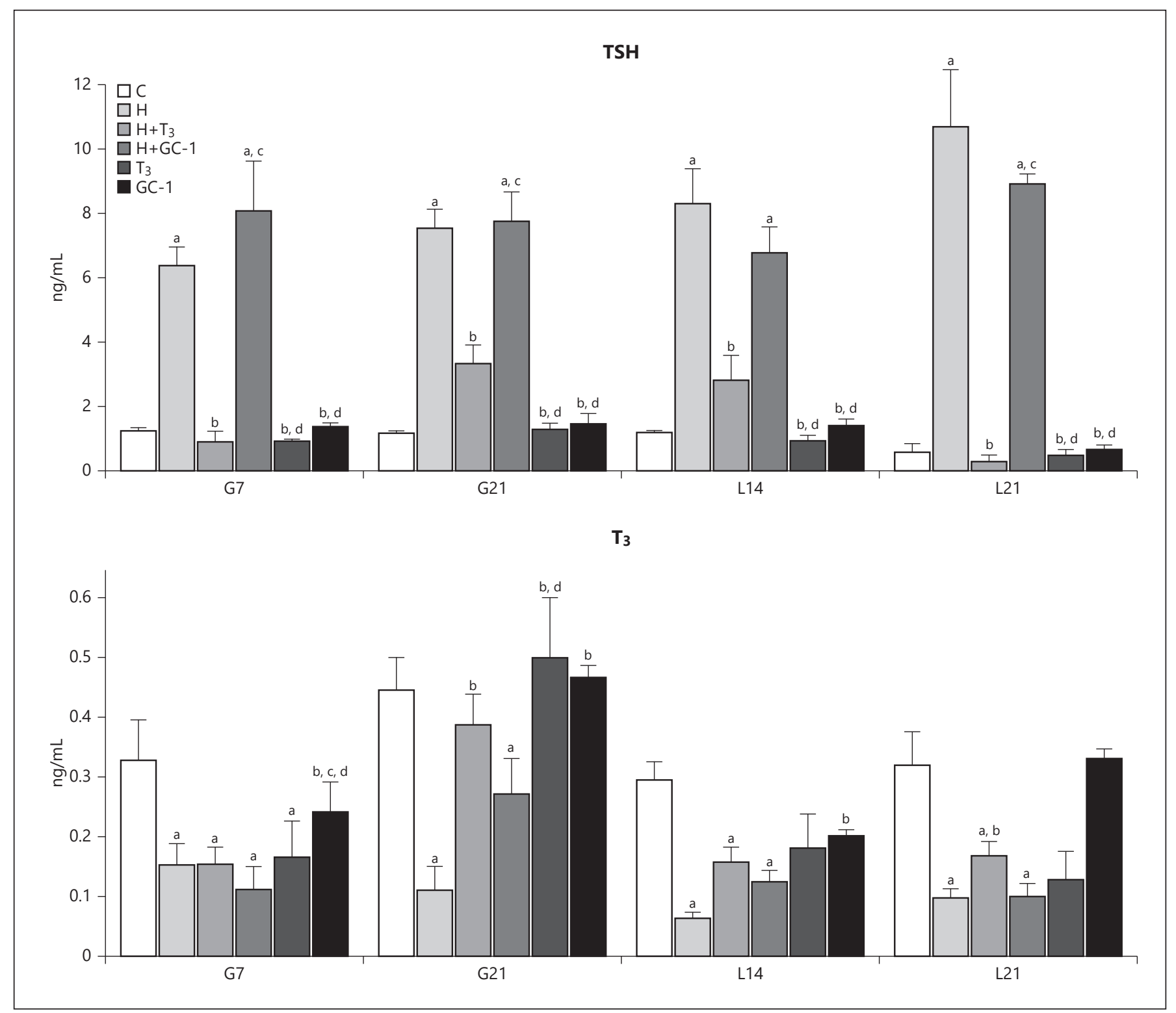

Fig. 1. TSH and T3 serum concentrations in rats during gestation and lactation treated with thyromimetic GC-1 or T3. Euthyroid (C), hypothyroid $(\mathrm{H})$, hypothyroid $\mathrm{T} 3$-treated $(\mathrm{H}+\mathrm{T} 3)$, hypothyroid GC-1-treated ( $\mathrm{H}+\mathrm{GC}-1)$, euthyroid T3-treated (T3), and euthyroid GC-1-treated (GC-1) rats. Hormonal profile was determined on G7 and G21 of gestation and on L14 and L21 of lactation. Hypothyroidism was induced by administering propylthiouracil in the drinking water at a concentration of $0.1 \mathrm{~g} / \mathrm{L}$. The values rep-

axis due to T3 administration $24 \mathrm{~h}$ earlier. T3 increased in the $\mathrm{H}+\mathrm{T} 3$ group at the end of gestation, reaching control levels. All groups had lower T3 levels than controls on L14. At the end of lactation, only T3 remained at control levels in the GC-1 group.

Effect of GC-1 on Reproduction and Lactation resent means \pm SEM ( $n=6-8$ rats per group). Kruskal-Wallis and Dunn post hoc tests were used to compare TSH levels and one-way ANOVA and Tukey post hoc tests to compare T3 levels between groups. G7 $F(5,25)=18.08, \mathrm{G} 21 F(5,53)=12.63, \operatorname{L} 14 F(5,46)=$ 9.958, and $\mathrm{L} 21 F(5,24)=8.983$. Statistical significance $(p<0.05)$ is indicated as follows: a versus $C$, b versus $H, c$ versus $H+T 3$, and d versus $\mathrm{H}+\mathrm{GC}-1$.

\section{Reproductive Performance}

Hypothyroidism reduced the number of implantation sites and of pups per litter (shown in Fig. 2). T3 or GC-1 administration overcame the effect of hypothyroidism. Parturition was delayed in $\mathrm{H}$ and $\mathrm{H}+\mathrm{GC}-1$ 
groups com pared to control, but $\mathrm{T} 3$ treatment reestablished the normal onset of labor. Lactational performance was evaluated in terms of pup body weight on L14. It was lower in PTU-treated groups $(\mathrm{H}, \mathrm{H}+\mathrm{GC}-1$, and $\mathrm{H}+\mathrm{T} 3$ ).

\section{TR Expression}

Different patterns of TR $\alpha 1$ and TR $\beta 1$ expression were simultaneously found in CL, placenta, uterus, and mammary glands of the same animal at the end of gestation (shown in Fig. 3).

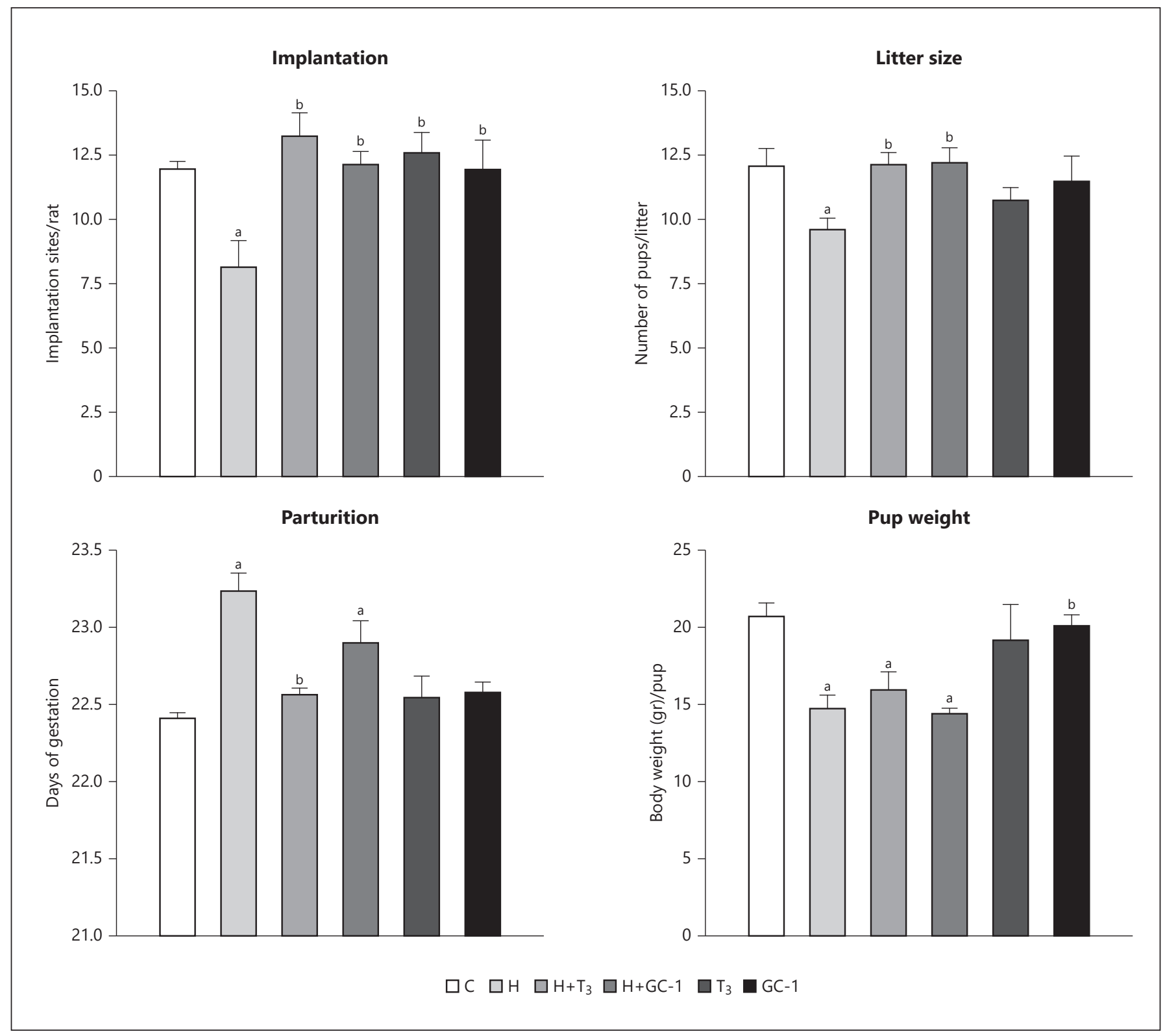

Fig. 2. Effects of T3 or GC-1 on reproductive performance of hypothyroid and euthyroid female rats. The number of uterine implantation sites on G7, date and time of parturition, number of total newborns per litter, and pup weight on L14 were registered for euthyroid (C), hypothyroid $(\mathrm{H})$, hypothyroid T3-treated $(\mathrm{H}+$ T3), hypothyroid GC-1-treated (H + GC-1), euthyroid T3-treated (T3), and euthyroid GC-1-treated (GC-1) rats. Hypothyroidism was induced by administering propylthiouracil in the drinking wa- ter at a concentration of $0.1 \mathrm{~g} / \mathrm{L}$. The values represent means \pm SEM ( $n=6-8$ rats per group). Kruskal-Wallis and Dunn post hoc tests were used to compare parturition, and one-way ANOVA and Tukey post hoc tests were used to compare implantation, litter size, and pup weight between groups. Implantation $F(5,41)=5.628$, litter size, $F(5,62)=4.332$, and pup weight $F(5,46)=9.958$. Statistical significance $(p<0.05)$ is indicated as follows: a versus $C$, b versus $\mathrm{H}$, and d versus $\mathrm{H}+\mathrm{GC}-1$. 
Effect of Maternal GC-1 and T3 Administration on the Regulation of Thyroid Axis, Pup Weight, and

\section{Survival}

Maternal hypothyroidism affected the survival and weight of pups $(p>0.001)$, regardless if mothers were treated or not with GC-1 or T3 (shown in Fig. 4). T3 treatment slightly altered pup survival $(p=0.0156)$. Administration of GC-1 alone did not affect pup weight or survival. Maternal PTU treatment rendered pups hypothyroid, as demonstrated by T4. T3 was not affected in pups of the $\mathrm{H}$ group, but it was reduced in those of the $\mathrm{H}+\mathrm{T} 3$ and $\mathrm{H}+\mathrm{GC}-1$ groups. TSH was higher in the pups of the $\mathrm{H}$ and $\mathrm{H}+\mathrm{GC}-1$ groups and lower in those of the $\mathrm{H}+\mathrm{T} 3$ group than in the $\mathrm{H}$ group. Maternal treatment with either GC-1 or T3 alone did not affect TSH levels in pups.

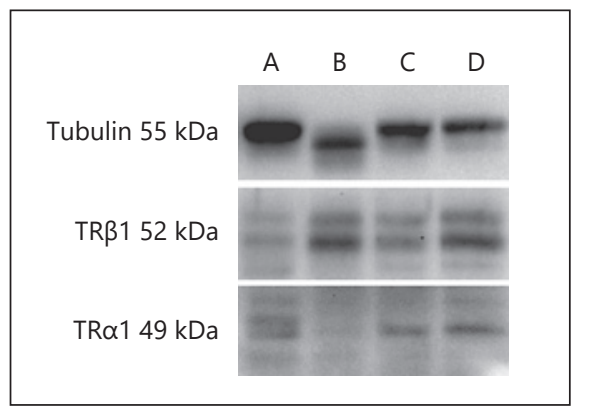

Fig. 3. Thyroid hormone receptor protein expression in reproductive tissues. (A) CL, (B) uterus, (C) placenta, and (D) mammary gland total proteins from a euthyroid rat were isolated and analyzed via Western blotting. Representative blots of TR $\alpha 1$, TR $\beta 1$, and tubulin protein expression are shown from the same animal on day G19 of gestation. CL, corpus luteum.

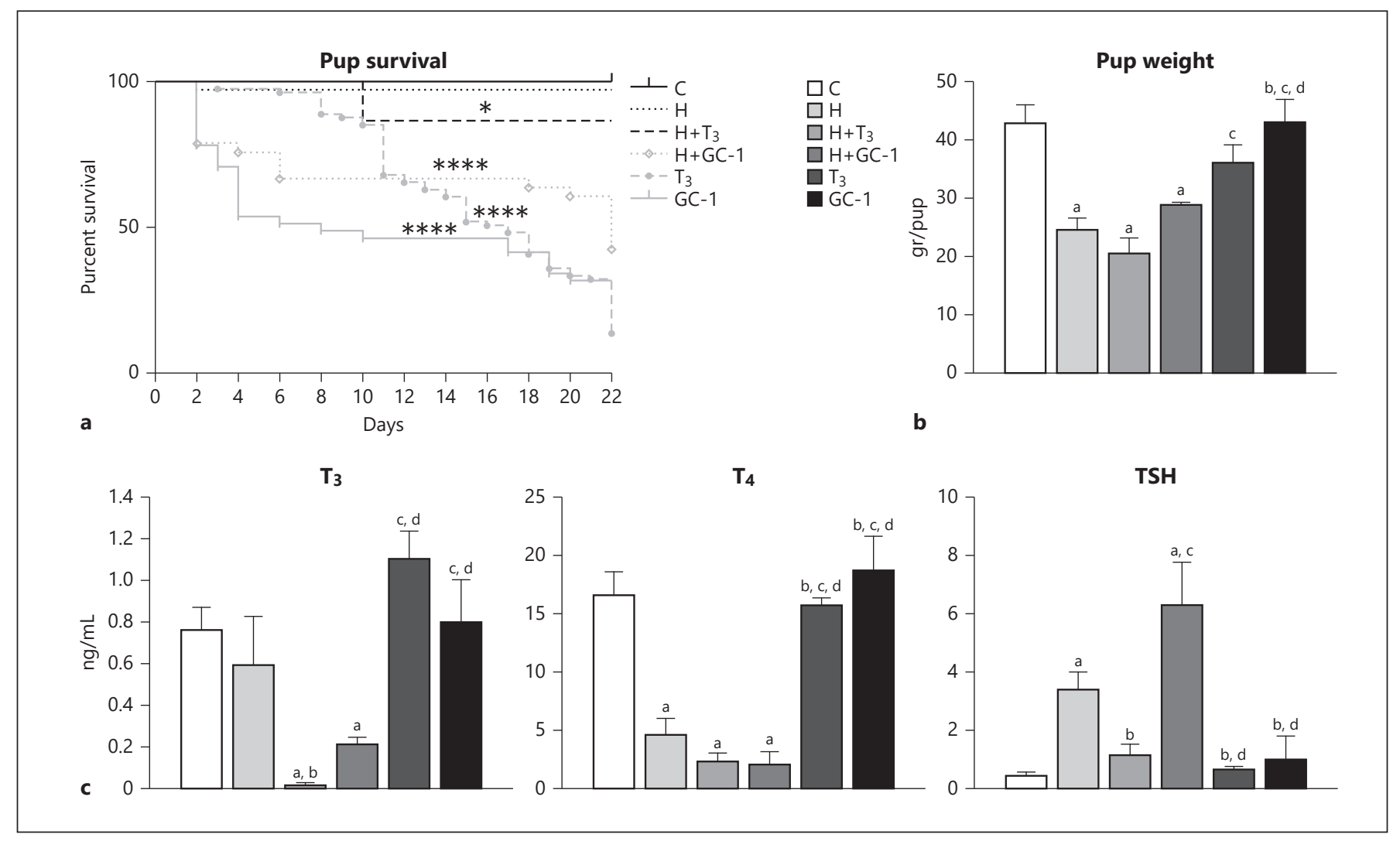

Fig. 4. Effect of maternal GC-1 and T3 administration on the regulation of thyroid axis, weight, and survival of pups. Pup survival and weight during lactation and T3, T4, and TSH serum concentrations were determined for euthyroid $(\mathrm{C})$, hypothyroid $(\mathrm{H})$, hypothyroid T3-treated $(\mathrm{H}+\mathrm{T} 3)$, hypothyroid GC-1-treated $(\mathrm{H}+$ GC-1), euthyroid T3-treated (T3), and euthyroid GC-1-treated (GC1) rats. a Kaplan-Meier survival curves of pups during lactation. Statistical differences between groups were evaluated using the log-rank (Mantel-Cox) test. ${ }^{*} p<0.05,{ }^{* *} p<0.01,{ }^{* * *} p<0.001$, and ${ }^{* * * *} p<0.0001$ with respect to the control group. b Pup weight at the end of lactation (L21). c T3, T4, and TSH serum concentrations in pups. Hypothyroidism was induced by administering propylthiouracil in the drinking water at a concentration of $0.1 \mathrm{~g} / \mathrm{L}$. The values represent means $\pm \operatorname{SEM}$ ( $n=6-8$ rats per group). Oneway ANOVA and Tukey post hoc tests were used to compare pup weight and T3, T4, and TSH levels between groups. Pup weight $F(5,20)=13.01$, T3 $F(5,18)=8.96$, T4 $F(5,16)=17.48$, and TSH $F(5,20)=9.101$. Statistical significance $(p<0.05)$ is indicated as follows: a versus $C$, b versus $H$, c versus $H+T 3$, and d versus $H+$ GC-1. 

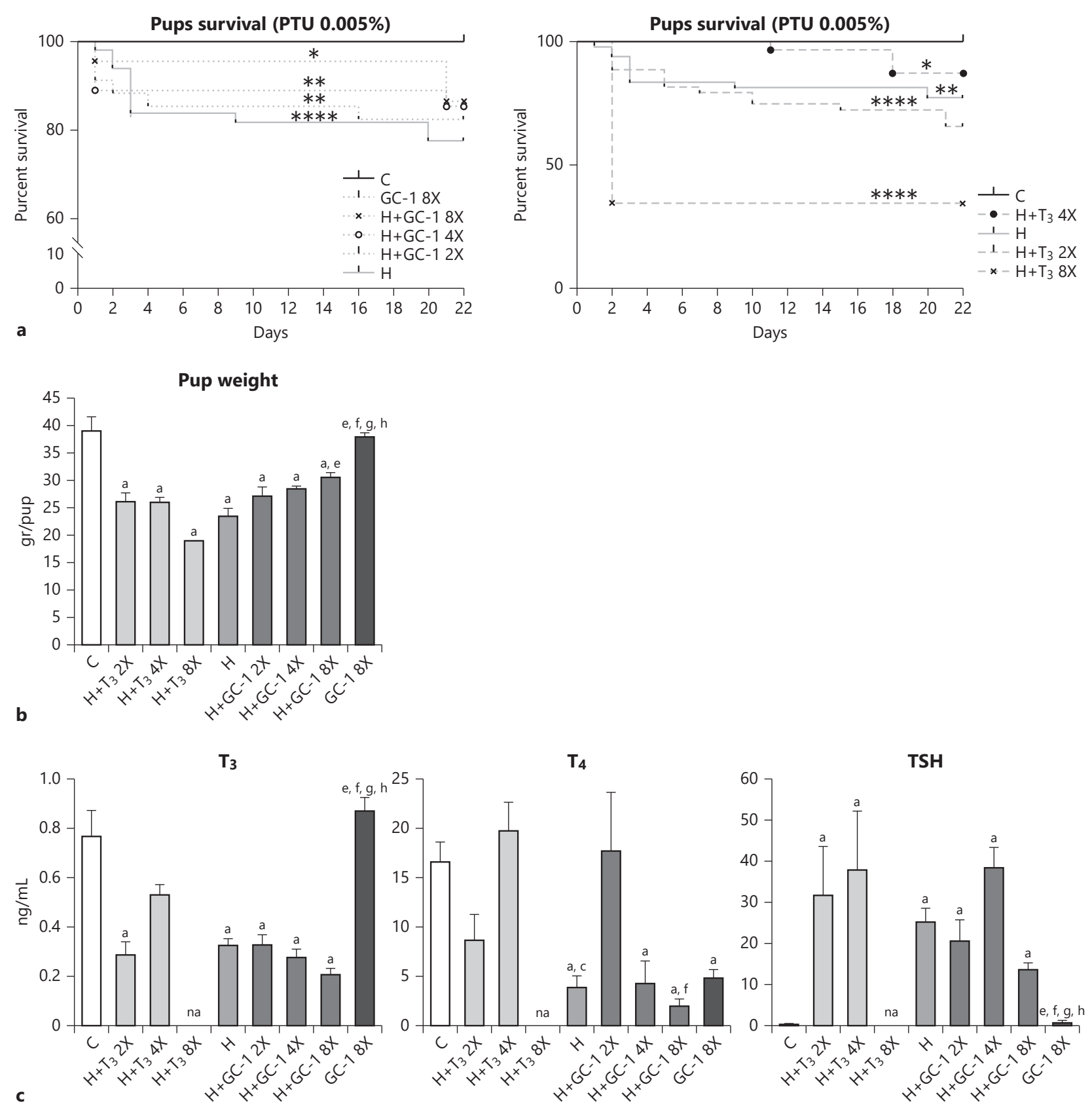

Fig. 5. Effect of maternal GC-1 and T3 administration on the regulation of thyroid axis, weight, and survival of pups. Pup survival and weight during lactation and T3, T4, and TSH serum concentrations were determined for euthyroid $(\mathrm{C})$, hypothyroid $(\mathrm{H})$, hypothyroid T3-treated $(\mathrm{H}+\mathrm{T} 32 \times, \mathrm{H}+\mathrm{T} 34 \times, \mathrm{H}+\mathrm{T} 38 \times)$, hypothyroid GC-1-treated (H + GC-1 2×, H + GC-1 4×, and H + GC-1 $8 \times$ ), and euthyroid GC-1 treated (GC-1 8x) rats. a Kaplan-Meier survival curves of pups during lactation. Statistical differences between groups were evaluated using the log-rank (Mantel-Cox) test. ${ }^{*} p<0.05,{ }^{* *} p<0.01,{ }^{* * *} p<0.001$, and ${ }^{* * * *} p<0.0001$ with respect to the control group. b Pup weight at the end of lactation (L21). c T3, T4, and TSH serum concentration in pups. Hypothyroidism was induced by the administration of propylthiouracil in the drinking water at a concentration of $0.05 \mathrm{~g} / \mathrm{L}$. The values represent means \pm SEM ( $n=6-8$ rats per group). To analyze pup weight, T3, T4, and TSH, after log transformation, one-way ANOVA and Tukey post hoc tests were used to compare between groups. Pup weight $F(7,29)=16.26$, T3 $F(7,26)=9.95$, T4 $F(7,24)=5.22$, and TSH $F(7,23)=31.43$. Statistical significance $(p<0.05)$ is indicated as follows: a versus $\mathrm{C}$, e versus $\mathrm{H}$, $\mathrm{f}$ versus $\mathrm{H}+\mathrm{GC}-12 \times$, g versus $\mathrm{H}+\mathrm{GC}-14 \times$, and h versus H + GC-1 8×. f, g, and h were compared within the groups treated with GC-1. 
GC-1 maternal administration did not interfere with the normal regulation of the thyroid axis of pups.

\section{Dose-Dependent Effect of Maternal GC-1 and T3} Administration on Thyroid Axis, Pup Weight, and Survival

The effect of maternal administration of dose-dependent GC-1, T3, and $0.05 \mathrm{~g} / \mathrm{L}$ PTU was evaluated in pups (shown in Fig. 5). A maximal maternal dose of GC-1 (GC$18 \times$ ) during lactation was also tested. All groups treated with PTU showed reduced pup weight and survival compared to controls but to a lesser extent than those treated with a double dose of PTU (online suppl. Fig. 4). T3 treatment did not revert PTU effects. The $\mathrm{H}+\mathrm{T} 38 \times$ group was the most affected, showing significantly higher perinatal mortality than $\mathrm{H}$ and $\mathrm{C}$ groups. However, GC-1 administration in the $\mathrm{H}+\mathrm{GC}-18 \times$ group led to a more rapid pup weight gain than $\mathrm{H}$. Administration of GC-1 $8 \times$ did not affect pup weight. Thyroidal axis was also influenced. TSH increased and T3 diminished in all groups treated with PTU, evidencing the hypothyroid state of pups. Administration of GC- $18 \times$ to lactating mothers reduced T4 levels but did not affect TSH or T3 levels in pups.

\section{Discussion/Conclusion}

The coordinated function of the CL, placenta, and uterus in rats allows the maintenance of gestation and initiation of labor. After birth, the mammary gland is essential for the fulfillment of lactation. These tissues differentially express TR subtypes depending on the physiological state, but it is challenging to demonstrate in vivo how TH signaling promotes a certain outcome $[10,25-$ 27]. GC-1 allowed us to differentiate TR selective actions in vivo, from initiation of gestation until newborns are capable of living on their own at weaning.

During pregnancy, the maternal thyroid axis is regulated depending on the demands of fetuses, increase in plasma volume, and $\mathrm{TH}$ synthesis and binding proteins. Euthyroid mothers adjust to these changes by modifying their TH metabolism, iodine uptake, and thyroidal axis [2]. PTU administration increased TSH as expected, and its effect was compensated by T3 treatment. GC- 1 at equimolar doses did not reestablish TSH levels. This was predictable, as the regulation of TSH by THs at the pituitary is mediated exclusively by the TR $\beta 2$ selective signaling [28]. GC-1 alone (36 nmoL/kg/day) did not disturb the normal regulation of TSH, confirming the specificity of

Effect of GC-1 on Reproduction and Lactation the thyroid analog. Other authors obtained comparable results when administering GC-1 at doses above 154 $\mathrm{nmoL} / \mathrm{kg} /$ day [20]. T3 was most affected during lactation, reflecting the increased demands to produce milk. The administration of GC-1 did not disturb the TH axis during gestation and lactation when administered alone.

We further investigated the action of GC-1 on reproductive performance. Hypothyroidism diminished the number of embryos implanted in the uterus. T3 or GC-1 treatment of hypothyroid rats reestablished the number of implantation sites, suggesting that TR $\beta 1$ signaling plays a key role in the first stages of maternal and embryo interaction. Litter size reflected comparable results, revealing that the main reason for the lower number of pups was an alteration in the implantation process. We had previously reported that hypothyroidism diminishes litter size without interfering in ovulation, thus confirming that it impacts on the implantation process $[3,24]$. The present results evidence that THs are essential during this stage and that TR $\beta 1$ selective signaling is involved.

The exact mechanism associated with the initiation of labor in rats is not fully understood. However, it is known that the increase of estradiol levels at the end of gestation stimulates the synthesis and release of uterine prostaglandins, which then trigger uterine contraction. This, in turn, instigates the release of oxytocin by the posterior pituitary and the endometrium. In cooperation with relaxin produced by the CL, oxytocin then provokes parturition [29]. We confirmed that hypothyroidism delays parturition and T3 treatment reestablishes the normal length of pregnancy. In contrast, treatment with GC-1 did not hinder the delay in labor induction, suggesting that $\mathrm{TH}$ signaling mediated by $\mathrm{TR} \alpha 1$ is critical at the end of gestation. This assumption is further supported by our result that TRal is simultaneously present at the end of gestation in the CL, placenta, and uterus. Likewise, the lack of THs at the end of gestation delays parturition due to a postponement of luteal regression and a surge of prostaglandins [11].

Lactation is another critical stage regulated by THs. Postnatal exposure to antithyroid drugs and hormones through the maternal feeding has important consequences for pups. Thus, we examined the indirect outcome of maternal hypothyroidism and T3 or GC-1 treatment on pup weight, survival, and thyroid status. Maternal PTU treatment adversely affected pup weight, which was reflected in lower pup weight at the time of weaning. Treatment with active TH T3 or its TR $\beta$ selective analog could not defeat the antithyroid effects. These results evidence that PTU is responsible for those outcomes. Although it 
has been reported that PTU usage during lactation is preferred to other antithyroid drugs due to its lower passage into breast milk, it has also been demonstrated that it may be hepatotoxic $[1,30]$. As expected, the passage of PTU through milk induced hypothyroidism. Maternal treatment with supraphysiological doses of $\mathrm{T} 3$ also had a detrimental effect on pup survival and weight. Meanwhile, maternal administration of GC-1 at equimolar doses resulted innocuous, as it did not affect pup survival, weight gain, or thyroidal status.

PTU reduction increased pup survival, confirming the presumption that PTU negatively affects the health of the newborns. Despite the negative effect of hypothyroidism induced by PTU, treatment with GC-1 improved the well-being of the pups in terms of survival and weight gain in a dose-dependent manner. It thus may be assumed that TR $\beta 1$ selective signaling plays a significant role in mammary gland activity, pup weight gain, and survival during lactation.

The relevance of our findings for humans might be limited, given that the mechanism triggering parturition in the rat is not fully understood. However, the physiology of the uterus and cervix during parturition, as well as that of the mammary gland, is similar in rats and humans. The biological concepts developed based on the rat model may thus be enlightening for human reproduction and lactation.

In conclusion, this work demonstrates that THs play a vital role in the reproductive process. It also suggests that TR $\alpha$ selective signaling is critical at the end of gestation and leads to a normal onset of parturition. The use of the selective TR $\beta$ agonist GC-1 may be useful for the treatment of hypothyroidism during lactation, as it prevents the detrimental effects of TRa signaling during this period. As far as we know, this is the first time that evidence is provided about the effect of the maternal TR $\beta$ selective agonist GC-1 on the reproductive process and its indirect impact on the pups.

\section{Acknowledgements}

The authors are indebted to Elisa Pietrobon and Matilde di Paola for their excellent technical support and to Emilia Gamarra and Dr. Mariella Superina for the English language editing of the manuscript. The authors thank Dr. Scanlan for supplying the thyromimetic GC-1.

\section{Statement of Ethics}

Animal maintenance and handling was performed according to the Guiding Principles in the Care and Use of Laboratory Animals of the US National Institutes of Health (NIH Publication No. 86-23, revised 1985 and 1991) and the United Kingdom's requirements for ethics of animal experimentation (Animals Scientific Procedures, Act 1986). All procedures were approved by the Institutional Animal Care and Use Committee of the School of Medical Science, National University of Cuyo, Mendoza, Argentina (Protocol Approval No. 17/2012 and 67/2015).

\section{Conflict of Interest Statement}

The authors have no conflicts of interest to disclose.

\section{Funding Sources}

This work was supported by the research grants PICT PB 2014_2604 from Agencia MINCYT Argentina and SIIP 06/M114 FCEN Universidad Nacional de Cuyo. M.B.H., C.G.L., and F.C.V.A. are Career Scientists at CONICET, and E.R. has fellowships from CONICET.

\section{Author Contributions}

E.R., F.C.A., M.B.H., and C.G.L. performed the in vivo studies, hormonal determinations, and Western blots, analyzed the data, and prepared the figures. M.E. discussed and analyzed the data. M.B.H. and C.G.L. supervised the study and analyzed and discussed the data. M.B.H. wrote the manuscript. All authors discussed and edited the manuscript.

\section{References}

1 Karras S, Krassas GE. Breastfeeding and antithyroid drugs: a view from within. Eur Thyroid J. 2012 Apr;1(1):30-3.

2 Alexander EK, Pearce EN, Brent GA, Brown RS, Chen H, Dosiou C, et al. 2017 guidelines of the American Thyroid Association for the diagnosis and management of thyroid disease during pregnancy and the postpartum. Thyroid. 2017 Mar;27(3):315-89. Erratum in: Thyroid. 2017 Sep;27(9):1212.
3 Hapon MB, Simoncini M, Via G, Jahn GA. Effect of hypothyroidism on hormone profiles in virgin, pregnant and lactating rats, and on lactation. Reproduction. 2003 Sep;126(3): 371-82.

4 Hapon MB, Varas SM, Jahn GA, Giménez MS. Effects of hypothyroidism on mammary and liver lipid metabolism in virgin and latepregnant rats. J Lipid Res. 2005 Jun;46(6): 1320-30.
5 Ziegelmüller B, Vattai A, Kost B, Kuhn C, Hofmann S, Bayer B, et al. Expression of thyroid hormone receptors in villous trophoblasts and decidual tissue at protein and mRNA levels is downregulated in spontaneous and recurrent miscarriages. J Histochem Cytochem. 2015 Jul;63(7):511-23. 
6 López Navarro E, Ortega FJ, Francisco-Busquets E, Sabater-Masdeu M, Álvarez-Castaño E, Ricart W, et al. Thyroid hormone receptors are differentially expressed in granulosa and cervical cells of infertile women. Thyroid. 2016 Mar;26(3):466-73.

7 Vattai A, Ziegelmüller B, Kost B, Kuhn C, Hofmann S, Bayer B, et al. The expression of thyroid hormone receptors (THR) is regulated by the progesterone receptor system in first trimester placental tissue and in BeWo cells in vitro. Eur J Obstet Gynecol Reprod Biol. 2015 Dec;195:31-9.

8 Charalampoudis P, Agrogiannis G, Kontzoglou K, Kouraklis G, Sotiropoulos GC. Thyroid hormone receptor alpha (TRa) tissue expression in ductal invasive breast cancer: a study combining quantitative immunohistochemistry with digital slide image analysis. Eur J Surg Oncol. 2017 Aug;43(8):1428-32.

9 Shao W, Kuhn C, Mayr D, Ditsch N, Kailuweit M, Wolf V, et al. Cytoplasmic and nuclear forms of thyroid hormone receptor $\beta 1$ are inversely associated with survival in primary breast cancer. Int J Mol Sci. 2020 Jan 3;21(1): 330 .

10 Navas PB, Redondo AL, Cuello-Carrión FD, Roig LM, Valdez SR, Jahn GA, et al. Luteal expression of thyroid hormone receptors during gestation and postpartum in the rat. Thyroid. 2014 Jun;24(6):1040-50.

11 Hapon MB, Motta AB, Ezquer M, Bonafede M, Jahn GA. Hypothyroidism prolongs corpus luteum function in the pregnant rat. Reproduction. 2007 Jan;133(1):197-205.

12 Hapon MB, Varas SM, Giménez MS, Jahn GA. Reduction of mammary and liver lipogenesis and alteration of milk composition during lactation in rats by hypothyroidism. Thyroid. 2007 Jan;17(1):11-8.

13 Campo Verde Arboccó F, Sasso CV, Actis EA, Carón RW, Hapon MB, Jahn GA. Hypothyroidism advances mammary involution in lactating rats through inhibition of PRL signaling and induction of LIF/STAT3 mRNAs. Mol Cell Endocrinol. 2016 Jan 5; 419:18-28.
14 Campo Verde Arboccó F, Persia FA, Hapon MB, Jahn GA. Hypothyroidism decreases JAK/STAT signaling pathway in lactating rat mammary gland. Mol Cell Endocrinol. 2017 Jul 15;450:14-23.

15 Kaneshige M, Suzuki H, Kaneshige K, Cheng J, Wimbrow H, Barlow C, et al. A targeted dominant negative mutation of the thyroid hormone alpha 1 receptor causes increased mortality, infertility, and dwarfism in mice. Proc Natl Acad Sci U S A. 2001 Dec 18;98(26): 15095-100.

16 Göthe S, Wang Z, Ng L, Kindblom JM, Barros AC, Ohlsson C, et al. Mice devoid of all known thyroid hormone receptors are viable but exhibit disorders of the pituitary-thyroid axis, growth, and bone maturation. Genes Dev. 1999 May 15;13(10):1329-41.

17 Forrest D, Hanebuth E, Smeyne RJ, Everds N, Stewart CL, Wehner JM, et al. Recessive resistance to thyroid hormone in mice lacking thyroid hormone receptor beta: evidence for tissue-specific modulation of receptor function. EMBO J. 1996 Jun 17;15(12):3006-15.

18 Devereaux J, Ferrara SJ, Scanlan TS. Quantification of thyromimetic sobetirome concentration in biological tissue samples. Methods Mol Biol. 2018;1801:193-206.

19 Scanlan TS. Sobetirome: a case history of bench-to-clinic drug discovery and development. Heart Fail Rev. 2010 Mar;15(2):177-82.

20 Trost SU, Swanson E, Gloss B, Wang-Iverson DB, Zhang H, Volodarsky T, et al. The thyroid hormone receptor-beta-selective agonist GC-1 differentially affects plasma lipids and cardiac activity. Endocrinology. 2000 Sep; 141(9):3057-64.

21 Grover GJ, Egan DM, Sleph PG, Beehler BC Chiellini G, Nguyen NH, et al. Effects of the thyroid hormone receptor agonist GC-1 on metabolic rate and cholesterol in rats and primates: selective actions relative to $3,5,3^{\prime}$-triiodo-L-thyronine. Endocrinology. 2004 Apr; 145(4):1656-61.
22 Baxter JD Webb P, Grover G, Scanlan TS. Selective activation of thyroid hormone signaling pathways by GC-1: a new approach to controlling cholesterol and body weight. Trends Endocrinol Metab. 2004 May-Jun; 15(4):154-7.

23 Villicev CM, Freitas FR, Aoki MS, Taffarel C, Scanlan TS, Moriscot AS, et al. Thyroid hormone receptor beta-specific agonist GC-1 increases energy expenditure and prevents fatmass accumulation in rats. J Endocrinol. 2007 Apr;193(1):21-9.

24 Hapon MB, Gamarra-Luques C, Jahn GA. Short term hypothyroidism affects ovarian function in the cycling rat. Reprod Biol Endocrinol. 2010 Feb 11;8:14

25 Sayem ASM, Giribabu N, Muniandy S, Salleh N. Effects of thyroxine on expression of proteins related to thyroid hormone functions (TR- $\alpha$, TR- $\beta$, RXR and ERK1/2) in uterus during peri-implantation period. Biomed Pharmacother. 2017 Dec;96:1016-21.

26 Leonard AJ, Evans IM, Pickard MR, Bandopadhyay R, Sinha AK, Ekins RP. Thyroid hormone receptor expression in rat placenta. Placenta. 2001 Apr;22(4):353-9.

27 Campo Verde Arboccó F, Sasso CV, Nasif DL, Hapon MB, Jahn GA. Effect of hypothyroidism on the expression of nuclear receptors and their co-regulators in mammary gland during lactation in the rat. Mol Cell Endocrinol. 2015 Sep 5;412:26-35.

28 Nakano K, Matsushita A, Sasaki S, Misawa H, Nishiyama K, Kashiwabara Y, et al. Thyroidhormone-dependent negative regulation of thyrotropin beta gene by thyroid hormone receptors: study with a new experimental system using CV1 cells. Biochem J. 2004 Mar 1; 378(Pt 2):549-57.

29 Krinke GJ, Bullock GR, Bunton T. Reproduction and breeding. In. The Laboratory Rat. Handbook of experimental animals. Elsevier: 2000. p. 32-4.

30 Fumarola A, Di Fiore A, Dainelli M, Grani G, Carbotta G, Calvanese A. Therapy of hyperthyroidism in pregnancy and breastfeeding. Obstet Gynecol Surv. 2011 Jun;66(6): 378-85. 